\title{
Jak przekazywać naukową wiedzę w Internecie. \\ (Na marginesach kolekcji PrusPlus \\ w Nowej Panoramie Literatury Polskiej)
}

Barteomiej Szleszyński, Agnieszka Kochańska, KONRAD NicińsKi

(Instytut Badań Literackich PAN)

\section{Nowa Panorama Literatury Polskiej- GEÓWNE ZAŁOŻENIA}

Dziewiętnastego września 2015 r. oficjalnie, pod adresem nplp.pl, zainaugurowała swoją działalność Nowa Panorama Literatury Polskiej, jeden z projektów Centrum Humanistyki Cyfrowej przy Instytucie Badań Literackich PAN. Tworzenie pierwszej, pilotażowej kolekcji PrusPlus wiązało się z podjęciem licznych decyzji i dokonaniem weryfikacji wejściowych hipotez - o kilku najbardziej spektakularnych problemach chcieliśmy opowiedzieć $\mathrm{w}$ tym artykule.

Przyszły kształt NPLP jest czymś, co z perspektywy ukończenia jednej kolekcji i zaawansowanych prac nad drugą ${ }^{\mathrm{I}}$ możemy dopiero planować. Nie znaczy to jednak, że przedsięwzięciu nie towarzyszą założenia natury ogólnej. Można wyrazić je następująco:

Nowa Panorama Literatury Polskiej to platforma służąca pre-
zentacji wyników badań naukowych w środowisku cyfrowym, łącząc
próby wypracowania nowych form prezentacji wyników badań z ja-

1 Kolekcja Atlas Polskiego Romantyzmu jest dostępna publicznie pod adresem http://nplp.pl/kolekcja/ atlas-romantyzmu, choć niektóre jej hasła pozostają jeszcze w budowie. 
kością treści właściwą dla instytucji naukowej o długoletniej tradycji badawczej i najwyższej ocenie parametrycznej².

Zakładamy, że jest ona szansą na zaistnienie literaturoznawstwa (i w ogóle humanistyki) w przestrzeni cyfrowej. Dzięki specyfice medium możemy uzyskać: szeroki zasięg (nieporównywalnie większy niż w przypadku książek papierowych); korzystny współczynnik kosztów do zasięgu (co jest fundamentem wszelakich działań upowszechniających albo popularyzujących wiedzę); wykluczenie problemów związanych z tradycyjnie pojętą dystrybucją; możliwość dotarcia do osób, które nie czytają papierowych publikacji naukowych lub nie mają do nich dostępu. Zakładamy (wiele przesłanek i doświadczeń na to wskazuje) ${ }^{3}$, że istnieje duże zapotrzebowanie na treści wysokiej jakości (oznaczone wyraźnym „znakiem jakości”) - i NPLP wychodzi naprzeciw temu zapotrzebowaniu. Powyższe założenia zostaną zweryfikowane za jakiś czas, gdy w NPLP zostanie umieszczona większa liczba kolekcji, a także gdy zostaną przeprowadzone działania promocyjne (zarówno w przestrzeni cyfrowej, jak i „realnej”).

Oczywiście, należy zdawać sobie sprawę z ograniczeń, które wiążą się z projektami internetowymi. Po pierwsze, choć zasięg kolekcji cyfrowych jest potencjalnie znacznie większy niż publikacji tradycyjnych, to ogranicza się do osób posiadających dostęp do Internetu - nie należy zapominać, że wiele osób go nie posiada. Po drugie, mimo braku przeszkód związanych z tradycyjną dystrybucją książek, warunkiem stabilnej działalności NPLP jest zaplecze technologiczne, którego utrzymanie i serwisowanie generuje koszty. Po trzecie zaś, aby uzyskać szerokie grono użytkowników, niezbędne są działania promocyjne w przestrzeni internetowej i poza nią.

Założeniem - które przyświecało tworzeniu NPLP - było, oprócz publikacji wysokiej jakości treści naukowych, stworzenie nowoczesnej i jednocześnie adekwatnej do tych treści struktury, formy wizualnej i funkcjonalności.

Dla Nowej Panoramy Literatury Polskiej, w odróżnieniu od dotychczasowej Panoramy Literatury Polskiej ${ }^{4}$, projektu opartego na koncepcji encyklopedii in-

2 O Nowej Panoramie Literatury Polskiej, http://nplp.pl/o-nowej-panoramie-literatury-polskiej/ (stan z 7 stycznia 2016 r.).

3 Świadczą o tym m.in. popularność serwisu culture.pl prowadzonego przez Instytut Adama Mickiewicza, mającego zdecydowanie popularny charakter, niemniej jednak często utożsamiany ze źródłem wiedzy o jednoznacznej wartości naukowej (wskazuje na to duża częstotliwość wykorzystywania przypisów do culture.pl w polskiej Wikipedii), a także informacje usłyszane przez piszących te słowa dzięki współpracy z Komitetem Głównym Olimpiady Literatury i Języka Polskiego.

4 Panorama Literatury Polskiej (panoramaliteratury.pl) to poprzedni internetowy projekt Instytutu Badań Literackich PAN, który, głównie ze względu na trudną sytuację finansową polskiej humanistyki przed kilkoma laty, nie mógł zostać zrealizowany w satysfakcjonujacy sposób (choć z myślą o tej stronie powstało wiele wartościowych tekstów, które planujemy wykorzystać w Nowej Panoramie Literatury Polskiej). Szanując dorobek poprzedników, w NPLP zmodyfikowaliśmy założenia 
ternetowej, uzgodniono (także w oparciu o wcześniejsze jej koncepcje powstałe w CHC oraz podczas dyskusji z Dyrekcją Instytutu Badań Literackich PAN) formę zbioru kolekcji, które określić można mianem „syntezy rozproszonej”. Autorską koncepcją piszących te słowa było stworzenie z każdej z kolekcji swoistej i spójnej „naukowej opowieści cyfrowej“ - proponujemy narrację, za którą czytelnik / użytkownik może podążać - chcemy, by „zanurzył się” w opowieści (odwołujemy się do pojęcia immersji ${ }^{5}$, stosowanego w badaniu gier video). Oczywiście dla użytkownika, który poszukuje konkretnych kwestii strona nplp.pl oferuje możliwość przeszukiwania treści.

Wymienione wyżej założenia mają duży poziom ogólności - z uwagi na to dalsza część artykułu poświęcona będzie temu, jakie konkretne rozwiązania wykorzystane zostały w kolekcji PrusPlus w celu realizacji tychże założeń.

\section{Kolekcja $P_{R U S} P_{L U S}$}

Przenoszenie treści z papierowej książki do Internetu musi wiązać się z dostosowaniem m.in. struktury treści (w książce - linowej, w internecie - zhierarchizowanej), formy typograficznej - inaczej uzyskuje się czytelność tekstu na ekranie, inaczej na zadrukowanej stronie, wreszcie zaplanowanie funkcjonalności w taki sposób, by odbiorca w możliwie intuicyjny sposób przemieszczał się po materiale kolekcji cyfrowej.

Forma cyfrowa daje również możliwości nieosiągalne w takim stopniu w publikacjach papierowych: możliwość stosowania wielokrotnej kategoryzacji do tego samego materiału, różne formy przeszukiwania treści, powiązania hiperlinkowe pomiędzy materiałami, powiązanie narracji i przestrzeni (mapy) czy powiązanie tekstu i materiałów wizualnych.

W dalszej części artykułu skupimy się na konkretnych przykładach, w których ojawiają się powyższe kwestie.

projektu, położyliśmy także większy nacisk na stronę wizualną i budowanie struktur „naukowych opowieści”.

5 Termin ten, często wykorzystywany przy okazji oglądu krytycznego i badawczego gier video zdefiniować można jako: „doświadczenie zatracenia się poczucia swojego ciała w teraźniejszości przy jednoczesnej koncentracji na zmodyfikowanym środowisku; [...] pojęcia immersji używa się [...] na określenie różnych rodzajów doświadczeń zapośredniczonych przez ekran, w których podmiot «traci kontakt» z bezpośrednim fizycznym otoczeniem“ (za: J. Dovey, H. W. Kennedy, Kultura gier komputerowych, tłum. T. Macios, A. Oksiuta, Kraków 2011, s. 187). 


\section{Uwarunkowania Kolekcji $P_{R U S} P_{L U S}$}

Kolekcja PrusPlus wykorzystuje materiały powstałe podczas jubileuszowego dla pisarza roku 2012 - książkowy Leksykon Lalki ${ }^{6}$, niepublikowane dotąd materiały z sympozjum Powieściopisarze o Lalce ${ }^{7}$ oraz dostosowane do formy NPLP materiały z płyty Warszawy Prusa $^{8}$. Operowaliśmy zatem na materiale już istniejącym, „tłumacząc" go na formę cyfrową. W przyszłości zamierzamy także tworzyć materiały specjalnie na potrzeby kolekcji cyfrowych ${ }^{9}$.

\section{Struktura}

Struktura treści to zarówno pewnego rodzaju konieczność, jak i szansa na zbudowanie narracji dotyczącej materiału. W przypadku NPLP staliśmy przed wyzwaniem zaplanowania zarówno struktury całego serwisu, uwzględniającej również przyszłe kolekcje, jak i dla samej kolekcji PrusPlus.

Specyfika posiadanego materiału spowodowała, że naturalny był podział na trzy moduły, odpowiadające zbiorom materiałów - kolekcja zatem dzieli się na moduły: Leksykon Lalki, Powieściopisarze o Lalce oraz Warszawy Prusa.

Pierwszym zadaniem było wymyślenie struktury dla Leksykonu Lalki - przy około Ioo hasłach wyświetlanie ich wszystkich jednocześnie skutowałoby koniecznością długiego przewijania ekranów i utrudnienionym poruszaniem się wśród zgromadzonych materiałów. Naturalnym było więc wprowadzenie kategorii, w które moglibyśmy pogrupować odpowiednie hasła (oczywiście takie kategorie w pewien sposób narzucają pewien porządek lektury). Postanowiliśmy wypróbować rozwiązanie, które jest zdecydowanie wygodniejsze (i łatwiejsze w wykonaniu) w przestrzeni cyfrowej - zastosować dwa rodzaje kategoryzacji dla tego samego

6 Leksykon Lalki, red. A. Bąbel i A.Kowalczykowa, Warszawa 2011.

7 Jednym z wydarzeń towarzyszących obchodom Roku Prusa (2012) było zorganizowana przez Narodowe Centrum Kultury i Instytut Badań Literackich PAN dyskusja, której tematem była trwałość dziedzictwa Prusa dzisiaj, a uczestnikami - czołowi polscy pisarze i eseiści, m.in.: Magdalena Tulli, Inga Iwasiów, Anna Bolecka, Jan Tomkowski, Jerzy Sosnowski, Mariusz Sieniewicz, Radosław Kobierski, Marek Krajewski i prowadzący dyskusję Marek Bieńczyk.

8 Płyta Warszawy Prusa (koncepcja merytoryczna, koncepcja audiowizualna, scenariusz: B. Szleszyński, K. Niciński, K. Tuszyńska, projekt graficzny: K. Stanny) wydana została w 2012 roku przez Narodowe Centrum Kultury.

9 Innym istotnym działem humanistyki cyfrowej, którym zajmuje się Nowa Panorama Literatury Polskiej, jest edytorstwo cyfrowe. Na razie zespół NPLP uczestniczy w grancie Skamandrycka triada na emigracji. Edycja listów Jana Lechonia, Kazimierza Wierzyńskiego i Mieczystawa Grydzerwskiego (publikacja ksiażkowa i cyfrowa), odpowiadając m.in. za opracowanie podstandardu TEI (Text Encoding Iniciative) na potrzeby przygotowywanych listów, zaplanowanie i nadzorowanie prac nad stworzeniem edytora TEI, a także opatrzenie listów znacznikami TEI i wprowadzenie ich do bazy. 
materiału: kategorie standardowe: Bohaterowie, Filozofia, Miejsca, Historia, Rozrywki, Cywilizacja, Spoteczeństwo, Pitawal, Codzienność, Wtaściwości tekstu oraz niestandardowe (nieco prowokacyjne, zapraszające do przygody z tekstem i różnymi perspektywami jego lektury): Kobiety i kobiece sprawki, Mężczyźni i męskie zabawki, Podróże w czasie i przestrzeni, Ciato i duch, Żarty, swary, spory, Pamię́ i postęp, Marzyciele i marzenia lub Koszmary, przeczucia, traumy. Drugi rodzaj kategorii uczyniliśmy nierozłącznymi - tzn. jedno hasło może należeć do kilku kategorii niestandardowych (np. hasło Bale znajduje się zarówno w Kobiety i kobiece sprawki, jak i w Mężczyźni i męskie zabawki). Narzędzie zaprojektowane dla publikacji treści w NPLP pozwala na wprowadzenie właściwie dowolnej ilości kategoryzacji. Po wybraniu modułu Leksykon Lalki użytkownik przechodzi do wyboru kategorii, a dodatkowo dysponuje możliwością przełączania między kategoriami standardowymi i niestandardowymi.

Moduł Powieściopisarze o Lalce zawiera 8 tekstów, więc nie było potrzeby wprowadzania w nim dodatkowych elementów struktury.

W przypadku Warszaw Prusa struktura została zaplanowana już w aplikacji Z 2012 roku, tutaj należało ją jedynie przenieść do narzędzi narracyjnych NPLP. Ale ponieważ współtwórcami tej struktury byli dwaj z piszących te słowa, a do tego jest to przykład na jedną z możliwości oferowanych przez środowisko cyfrowe, omówimy tę sprawę szerzej przy okazji problemu powiązania przestrzeni i tekstu.

\section{Dostosowywanie treści. Czytelność a typografia}

Do tekstu głównego, bibliografii, przypisów, nawigacji na stronie wybrano bezszeryfowy ${ }^{\text {Io }}$ font Lato autorstwa Eukasza Dziedzica ${ }^{\mathrm{II}}$. Jego wyboru dokonano ze względu na czytelność, bezpłatność i przystosowanie do wielu znaków z innych języków (co przekłada się na obecność m.in. nazwisk obcojęzycznych w bibliografii). Font zaprojektowano także z myślą o wyświetlaniu na ekranach, wszystkie elementy liter są dobrze widoczne nawet w tekście o mniejszym stopniu kroju (czego nie spełniały testowane przez nas kroje szeryfowe w tekście głównym).

Do tytułów i podtytułów wybrano font Playfair Display autorstwa Clausa Eggersa Sørensena. To krój szeryfowy typu klasycystycznego (podobnego do rodzin

10 „Szeryfy, zaciosy [serifs] - poziome lub ukośne znaki zakończenia elementów znaków pisma, najczęściej w postaci prostokątów lub klinów." Krój bezszeryfowy pozbawiony jest tych znaków. (Cyt. za: J. Mrowczyk, Niewielki stownik typograficzny, Gdańsk 2008, s. 105).

11 http://www.lukaszdziedzic.eu (stan z 10 stycznia 2016 r.). 
krojów typu Didot czy Bodoni), dostępny tak jak Lato na otwartej licencji. Kroje dobierane były zgodnie z myślą, aby nie zaburzać stylu naukowego artykułów oraz aby swobodnie można było czytać dłuższe teksty (Lato).

\section{SZERoKość KOLUMNY I MARgINESY}

Myśląc o szerokości kolumny i wielkości marginesów, należało pamiętać o kilku kwestiach. Po pierwsze, strona będzie otwierana na różnych urządzeniach o różnych przekątnych ekranu, w przeciwieństwie do projektów typograficznych papierowych książek, gdzie omawiane przez nas elementy dostosowywane są w konkretnym przypadku do jednego, stałego formatu, np. A5.

Po drugie, ogólny projekt strony zorientowany jest na osadzaniu treści po lewej stronie ekranu. Jest to założenie odbiegające od przyzwyczajeń czytelniczych w sieci, gdzie aktualne projektowanie stron internetowych powiązanie jest $\mathrm{z}$ umieszczaniem treści w ich centrum. Nasze dotychczasowe testy wskazują, że lewostronny układ treści, mimo pewnego rodzaju niestandardowości, nie niweluje czytelności.

Po trzecie zaś mamy do czynienia z tekstami o różnej długości, także kilkunastostronicowymi, stąd komfort czytania nie może być zakłócany przez zbyt długie wersy lub zbyt mały margines. Należało także rozwiązać problem ewentualnego zbyt długiego przewijania strony przy bardzo długich artykułach (o tym więcej w Formatowaniu tekstu gtównego).

Obecnie kolumna, światło między wierszami i margines z lewej strony (trudny do ustalenia z jednej strony przez kompozycję lewostronną całego NPLP, z drugiej wymagający odpowiedniej wielkości, aby odbiorca mógł czytać płynnie) są wynikiem prób z przesuwaniem miejsca wyznaczonego kolumnie tekstu w zaprogramowanej strukturze artykułu i testów przeprowadzonych na pierwszych czytelnikach (zwracali oni uwagę np. na zbyt mały w pierwotnej wersji margines lewostronny, co rozpraszało ich podczas lektury).

\section{Formatowanie TEKSTU GEÓWNEgo}

Obecnie narzędzie NPLP oferuje kilka możliwości formatowania tekstu - dostępne są zarówno te możliwości, które automatycznie oferuje platforma WordPress, jak i te dodane przez programistów, specjalnie na potrzeby NPLP.W efekcie możemy m.in.:

- korzystać z kilku wielkości tytułów i śródtytułów;

- samodzielnie wydzielać akapity w wybranych miejscach; 
- dzielić bardzo długie teksty na kilka podstron (co rozwiązuje problem zbyt długiego przewijania obszernego tekstu);

- korzystać z intuicyjnego sposobu dodawania ilustracji głównej i wewnątrztekstowych, a także z galerii przechowywanych plików graficznych;

- dodawać do strony NPLP zakodowane filmy z serwisów typu YouTube czy Vimeo;

- tworzyć cytaty, bibliografię i przypisy - o nich szerzej za chwilę.

\section{Cytaty}

Zaprojektowane zostało też osobne wyróżnienie dla cytatów jedno- i dwuzdaniowych, które jest spójne z całym projektem strony (wyróżnienie poprzez „podkreślenie", obecne także w linkach, nagłówkach, pasku nawigacji). Wyrównanie tekstu do lewej strony w cytatach nie tylko niweluje problem nierównych odstępów w tekście wyjustowanym, lecz także współgra z lewostronnym projektem całej strony NPLP. Została dla nas zaprojektowana możliwość manipulacji wyróżnionym cytatem do lewej i do prawej strony tekstu głównego. Pełni to nie tylko funkcję estetyczną, lecz także rozbija monotonię układu dla odbiorcy czytającego większe partie tekstu na ekranie. Większe partie cytowane (np. akapity) zdecydowaliśmy się wyróżnić za pomocą klasycznych opcji typograficznych, jak kursywa czy cudzysłów (w zależności od redakcji całości kolekcji).

\section{PrZypisy i bibliografia}

Ze względu na naukowy charakter tekstów wydzieliliśmy ${ }^{\mathrm{I2}}$ odpowiedni obszar pod nimi dla bibliografii i przypisów, których wstawienie jest jedną z funkcji narzędzia stworzonego dla NPLP. Do przypisu przechodzimy, klikając na jego numer. Możemy także wrócić od przypisu z powrotem do danego miejsca w tekście przy użyciu ikony strzałki. Dzięki przyjętemu układowi tekstu na stronie Nowej Panoramy ilość przypisów jest nieograniczona.

12 Z uwagi na to, że platforma WordPress nie umożliwia stosowania domyślnie bibliografii i przypisów w takiej formie, jaką założyliśmy, zostały one dla nas specjalnie przygotowane i włączone do platformy przez zespół programistyczny. 


\section{WARSTWA WIZUALNA}

Do podstawowych pytań, na które należało odpowiedzieć podczas pracy nad pierwszymi kolekcjami NPLP, zaliczamy to o styl wizualny. Po pierwsze, w jakim stopniu platforma powinna zachować spójność wizualną? Kolekcje zamieszczone na platformie mogą dotyczyć różnych epok literackich, mają zróżnicowanych odbiorców, każda z nich ma odmienną strukturę kompozycyjną - stosownie do tego każda $\mathrm{z}$ nich powinna posiadać swój odrębny charakter wizualny. $Z$ drugiej strony jednak NPLP ma stanowić pewną całość, choćby jako nowa propozycja lektury i odbioru literatury polskiej, i w związku z tym warto, aby wszystkie kolekcje miały w swej identyfikacji wizualnej elementy wspólne. Oczywiście, taką częścią wspólną są strony wejściowe NPLP, prezentujące całość kolekcji. Chcieliśmy we wszystkich kolekcjach zachować podobieństwo układu strony pojedynczych haseł, w przekonaniu, że nie tylko służy to identyfikacji strony, ale także ułatwia lekturę. W obrębie kolekcji szukamy takiego przejścia do poszczególnych haseł, które najlepiej odpowiada jej strukturze, czyli na przykład w wypadku PrusPlus jest to zbiór fiszek z hasłami, a w Atlasie Romantyzmu Polskiego oczywiście mapa. Zakładamy jednak, że podobieństwa struktury powinny wiązać się z podobieństwem rozwiązań wizualnych. Stąd jeżeli kolekcja dzieli się wyraźnie na kilka odrębnych części, dążymy do tego, aby wizytówki owych części zachowały podobieństwo do wizytówek tych kolekcji na stronie głównej. W takim wypadku elementem przywołującym styl epoki, do której odnosi się kolekcja, jest bardziej ilustracja stanowiąca część wizytówki niż jej krój. To prowadzi do drugiego istotnego pytania, o proporcje między stylizacją a nowoczesnością. Priorytet atrakcyjności przekazu niewątpliwie wymusza nowoczesny styl projektu; stąd nacisk na walory użytkowe, chłodna prostota, szukanie urody nie w ozdobach, a w dobrych proporcjach. $Z$ drugiej strony jednak każda z kolekcji zawiera elementy, które w dyskretny sposób wprowadzają charakter epoki. Poza oczywistą rolą, jaką odgrywa materiał ilustracyjny, takim elementem jest „belka“ u góry każdej z kolekcji - stanowi ona element wspólny, a jednocześnie zawiera grafikę, która stanowi przetworzenie ilustracji z epoki i tematycznie ma się odwoływać do jej cech kluczowych. W tym celu wykorzystywane są także elementy charakterystyczne każdej z kolekcji, na przykład dyskretną stylizację na dawne mapy w Atlasie Romantyzmu Polskiego stanowi róża wiatrów na głównej mapie. Pewne napięcie między tradycją a nowoczesnością wykorzystywano także w sposobie przedstawienia materiałów ilustracyjnych. To one w największym stopniu przywołują styl epoki, o której kolekcja opowiada, z drugiej strony styl prezentacji jest możliwie nowczesny - gwoli atrakcyjności, ale nie tylko. Niekiedy taki sposób przedstawienia stanowi podkreślenie zaskakująco nowoczesnych dziś cech narracji charakterystycznych dla dawnych epok. Stąd jeżeli do prezentacji grafik prasowych 
z epoki w kolekcji PrusPlus najczęściej wykorzystywana jest kompozycja typu widescreen $^{\text {I3 }}$, to rozwiązanie owo ma także podkreślać zaskakująco nowoczesny charakter narracji prasy warszawskiej końca XIX wieku. Zresztą to, jak dobrze autentyczne grafiki z „Tygodnika Ilustrowanego“ prezentują się w tej konwencji, pośrednio taką tezę potwierdza.

Wracając na koniec do cech wspólnych - wyraźnym aktem nadania całej kolekcji charakteru pomostu między tradycją a nowoczesnością jest wykorzystanie logotypów według projektu czcionki autorstwa Władysława Strzemińskiego, tzw. alfabetu Strzemińskiego, opublikowanego po raz pierwszy w 1932 roku ${ }^{\mathrm{I}}$. Równocześnie stanowią one ukłon wobec tradycji polskiej kultury i wzór nowoczesnego projektowania, znakomicie odpowiadającego najnowszym tendencjom. Materiał ilustracyjny wykorzystywany przez NPLP pochodzi z różnych źródeł, jednak lwia część znajduje się w zbiorach Biblioteki Instytutu Badań Literackich PAN, co, jak się zdaje, stanowi najlepszą drogę prezentacji tych znakomitych, a nie dość powszechnie znanych materiałów, zawierających wiele unikalnych grafik, a także rysunków i fotografii.

\section{INTUICYJNOŚć}

Przyjmując zasadę immersyjności, musieliśmy przemyśleć kwestię intuicyjności nawigacji.

Zdecydowaliśmy, aby:

- poszczególne kolekcje i zawarte artykuły prezentowane były w formie kart-ikon;

- do nawigacji dodatkowo służył pasek informujący, w jakiej części danej kolekcji znajduje się aktualnie odbiorca. Klikając na elementy paska, może on swobodnie przełączać się między poszczególnymi poziomami kolekcji;

- hierarchiczna budowa każdego artykułu rozpoczynała się od ilustracji wyróżniającej mapy, tytułu i tekstu głównego. Na końcu umieszczono bibliografię i przypisy. Stały układ hierarchiczny zapewnia komfort lektury bez względu na moduł czy kolekcję.

$13 \mathrm{~T}$ j. wykorzystująca kompozycję szerokoekranową w proporcjach 16:9 lub zbliżonych; efekt wizualny jest charakterystyczny m.in. dla elektronicznych mediów informacyjnych.

14 Komunikat grupy a.r. nr 2, Łódź 1932. 


\section{PowiązANie PRZESTRZENi I TEKSTU}

Projekt Warszawy Prusa wykorzystuje fakt, że Bolesław Prus związany jest z Warszawą jako autor tekstów literackich, a także pisanych przez czterdzieści lat kronik. Jego największa powieść (wciąż tak ważna dla kultury polskiej) także bardzo mocno kojarzona jest z przestrzenią Warszawy. Planując sposób narracji, chcieliśmy zarówno wykorzystać potencjał warszawskości Prusa, jak i spróbować zmierzyć się z kilkoma niekoniecznie prawdziwymi stereotypami recepcyjnymi, upowszechniając rozpoznania dokonane w prusologii ostatnich dekad.

Z tego względu mechanizm narracyjny oparty jest na mapie Warszawy (z oczywistych względów jest to mapa miasta $z$ II połowy XIX stulecia). Mapa istnieje w trzech wersjach (różniących się kolorem oraz ikoną postaci, a także zestawem budynków-ikon, które na niej zaznaczono), odpowiadających trzem obszarom tematycznym: Warszawa Gtowackiego, Warszawa Prusa, Warszawa Wokulskiego. Warszawa Gtowackiego koncentruje się na zagadnieniach związanych z kulturą i cywilizacją II połowy XIX wieku (takich jak np. rozwój komunikacji miejskiej, rozbudowa i przesuwanie się centrum miasta, czy kwestie kanalizacji i wodociągów), Warszawa Prusa omawia problemy związane z postacią i światopoglądem pisarza (np. hasło Aleksander Gtowacki ukazuje kwestie relacji między pisarską personą nazwaną pseudonimem a życiem prywatnym zaś hasło Spirytyzm przynosi rozważania o roli tego zjawiska w życiu i poglądach pisarza), zaś Warszawa Wokulskiego koncentruje się na zagadnieniach związanych z Lalka.

Zagadnienia symbolizowane są przez ikony budynków umieszczone na mapie, zaprojektowane (przez Katarzynę Stanny, która tworzyła oprawę graficzną dla Warszaw Prusa) - niekiedy są to rzeczywiste budowle, powstałe na podstawie zdjęć z epoki (jak np. Cerkiew św. Aleksandra na Placu Saskim czy Filtry), czasami „wyobrażone” kreacje, takie jak kamienica Prusa czy sklep Wokulskiego, umieszczone w lokalizacjach uznanych za najbardziej prawdopodobne oraz narysowane na podstawie zbliżonych budynków z epoki. Ta forma graficzna już na poziomie formalnym zwraca uwagę na, akcentowaną później w treści, pewną umowność rekonstrukcji Warszawy na podstawie Lalki czy Warszawy z Kronik, zbudowanej na granicy rzeczywistości i fikcji.

Zagadnienia opisywane są za pomocą stworzonych przez autorów scenariusza haseł oraz filmów, na których wypowiadają się badacze twórczości' ${ }^{15}$ autora Lalki. Filmy pokazują zdjęcia i grafiki niektórych lokalizacji, a także dzisiejszy wygląd

15 Przewodnikami po Warszawach Prusa są badacze literatury i kultury XIX wieku: Barbara Bobrowska, Grażyna Borkowska, Agnieszka Bąbel, Ewa Paczoska, Marek Pąkciński, Włodzimierz Pessel i Bartłomiej Szleszyński. 
miejsc związanych z tematami zagadnień. Innymi słowy, niektóre obiekty, takie jak Cytadela, symbolizująca Powstanie Styczniowe, pojawiają się zarówno jako ikona (narysowana na podstawie wzoru z epoki), jak i jako rzeczywiste miejsce, sfilmowane współcześnie na potrzeby aplikacji. Na filmie pojawiają się także miejsca i wydarzenia przedstawione w kontekście epoki - np. plac Zamkowy podczas Powstania itp. Przeplatają się więc trzy rodzaje przestrzeni / miejsc / obiektów: zdjęcia i grafiki z epoki, dzisiejsze grafiki stworzone na podstawie grafik z epoki oraz sfilmowane współcześnie miejsca i obiekty. Dość dobrze odpowiada to głównym koncepcjom autorów scenariusza: po pierwsze, można szukać miejsc dawnych w dzisiejszej Warszawie, można poszukiwać korzeni pewnych współczesnych zjawisk cywilizacyjnych (np. transport miejski) w czasach Aleksandra Głowackiego, ale należy też pamiętać o tym, że zarówno przestrzeń, jak i obraz Warszawy - i całej epoki - zostały odtworzone, zrekonstruowane, skonfrontowane z dzisiejszymi zapotrzebowaniami i koncepcjami.

Mapa służy narracji - po kliknięciu na hotspot w pobliżu ikony wyświetla się krótki opis zagadnienia i link do materiałów na ten temat - artykułów, filmów i map ilustrujących konkretne zagadnienia. Ten trzeci rodzaj wykorzystania przestrzeni do opowiadania pewnych zagadnień wydaje się dosyć oczywisty, ale też dobrze pokazuje takie zagadnienia, jak fazy rozbudowy Warszawy, warszawską sieć transportową II połowy XIX wieku czy trasy spacerów Wokulskiego.

\section{Podsumowanie - w STRONĘ NOWYCH KOLEKCJI}

Kolekcja PrusPlus była pierwszą, całkowicie ukończoną - obecny tekst nie oddaje oczywiście wszystkich dylematów, które musieliśmy rozstrzygnąć. Liczymy jednak, że daje pewien obraz tego, ile decyzji trzeba było podjąć, aby stworzyć nie najbardziej przecież skomplikowaną formalnie kolekcję. W momencie, w którym piszemy te słowa, dostępny jest już Atlas Polskiego Romantyzmu, koncentrujący się na problematyce przestrzeni, rozwijający w znaczący sposób zagadnienia, nad którymi refleksję rozpoczęliśmy podczas prac nad Warszawami Prusa. Sukcesywnie dodawać będziemy także kolejne projekty, które niewątpliwie przysporzą nowych dylematów, ale i wzbogacą o liczne doświadczenia. Doświadczenia, którymi chętnie się podzielimy w stosownym czasie. 
B. Szleszyński, A. Kochańska, K. Niciński Jak przekazywać naukową wiedzę w Internecie

\section{Bibliografia:}

Dovey J., Kennedy H.W., Kultura gier komputerowych, tłum. Macios T., Oksiuta A., Kraków 2011;

Leksykon Lalki, red. A. Bąbel i A. Kowalczykowa, Warszawa 2011;

Mrowczyk J., Niewwielki stownik typograficzny, Gdańsk 2008;

Komunikat grupy a.r. nr 2, Łódź 1932;

Warszawy Prusa (koncepcja merytoryczna płyty CD, koncepcja audiowizualna, scenariusz: B. Szleszyński, K. Niciński, K. Tuszyńska, projekt graficzny: K. Stanny), Warszawa 2012.

\section{ŹRÓDEA INTERNETOWE:}

http://nplp.pl/kolekcja/atlas-romantyzmu;

http://nplp.pl/o-nowej-panoramie-literatury-polskiej;

http://www.lukaszdziedzic.eu (stan z 10 stycznia 2016 r.)

SŁOwA KLUcze: humanistyka cyfrowa, Bolesław Prus, romantyzm polski, Rok Prusa

\section{Barteomiej Szleszyński, Agnieszka Kochańska, KonRAd NicińsKi}

\section{How to Communicate Scholarly Knowledge on the Internet: Remarks on the 'PrusPlus' Collection, New Panorama of Polish Literature}

Nowa Panorama Literatury Polskiej (The New Panorama of Polish Literature, NPLP.PL) is a platform for the presentation of research results in the digital environment. It is a part of the Digital Humanities Centre at the Institute of Literary Research of the Polish Academy of Sciences. It consists of separate collections, each telling a different "scientific story" and using a different form to present content. The interdisciplinary team of the New Panorama of Polish Literature, includes literary and culture researchers, graphic designers and typographers.

Key words: digital humanities, Bolesław Prus, Polish Romanticism, The Year of Prus 